1 Tree Shade Coverage Optimization in an Urban Residential Environment

2 Qunshan Zhao ${ }^{\text {a1 }}$, Elizabeth A. Wentz ${ }^{\mathrm{a}}$, Alan T. Murray

3

$4 \quad{ }^{\mathrm{a}}$ Center for Geographical Information Science

5 School of Geographical Sciences and Urban Planning

6 Arizona State University

7 Tempe, AZ 85287-5302, USA

8 Email:

9 Qunshan Zhao: qszhao@asu.edu

10 Elizabeth A. Wentz: wentz@asu.edu

11

12

${ }^{\mathrm{b}}$ Department of Geography

13 University of California at Santa Barbara

14 Santa Barbara, CA 93106, USA

15 Email:

16 Alan T. Murray: amurray@ucsb.edu

\title{
$17{ }^{1}$ Corresponding author: Qunshan Zhao
}

18 Email: qszhao@asu.edu

19 Postal address:

201235 S Dorsey Ln. Apt 201

21 Tempe, AZ, 85281, USA

22 Telephone: $+1(480) 2806586$ 
Tree Shade Coverage Optimization in an Urban Residential Environment

\begin{abstract}
Shade provided by trees, shrubs and other vegetation serves as a natural umbrella to mitigate insolation absorbed by features of the urban environment, especially building structures. For a desert community, tree shade is a valuable asset, contributing to energy conservation efforts, improving home values, enabling cost savings, and promoting enhanced health and well-being. Therefore, maximizing tree shade coverage is an important component in creating an eco-friendly and sustainable urban environment. Strategic placement of trees enhances tree shade coverage of buildings. This paper details an optimization method to simultaneously maximize tree shade coverage on building facades and open structures and to minimize shade coverage on building rooftops in a 3-dimensional environment. This method integrates geographic information systems and spatial optimization approaches for placing trees that provide the greatest potential benefit to a building. A residential area in Tempe, Arizona is utilized to demonstrate the capabilities of the method. The optimization results show that two trees can provide up to $22.20 \mathrm{~m}^{2}$ shade coverage at $12: 00$ across a $54 \mathrm{~m}^{2}$ south-facing façade. This research offers a method to help homeowners, urban planners, and policy makers to quantitatively evaluate shade coverage from trees for building structures in a residential environment.
\end{abstract}

Key words: Tree shade coverage, spatial optimization, location modeling, solar insolation, GIS.

\title{
1. Introduction
}

The urban heat island (UHI) is the consequence of the thermal properties of the urban fabric that results in higher temperatures in urban areas compared to the surrounding rural areas [1-3]. The UHI exacerbates heat waves during the summer, increases energy consumption, and more importantly, increases the risk of heat-related morbidity and mortality, especially for the elderly, children, and disadvantaged groups [4-7]. Well-known UHI mitigation methods rely on increased vegetation such as shading impervious surfaces through increased tree coverage, building urban parks with lawns and water ponds, and adding green roofs or cool roofs on residential and commercial buildings [8-15]. In this research, we focus on the strategic planning of shade trees in residential areas, which has been shown to provide significant energy and long-term cost savings, to enhance the environmental quality of the urban ecosystem, and to promote a range of human health benefits [8,16-18]. Intuitively, the benefits of shade are best realized when trees are located on the sunward facing facade of buildings such as the west and southwest of a building for regions in the northern hemisphere. A simple method to create ample shade involves planting as many trees as possible on these sides of the building. This approach, however, is impractical because of the financial cost of trees as well as water restrictions in many water regulated communities [19]. Similarly, excessive shading reduces the possibility of retaining exposed residential rooftops for placing electricity-generating solar panels [20-23]. So while existing research provides a general guideline on where to locate residential trees, they fail to consider the position of windows and doors, residential landscape siting restrictions, and the rooftop solar energy loss from shade coverage [24-28]. The challenge, however, is achieving the maximum benefits of shade at the individual building structure level with a more quantitative method, something that is not fully understood [29,30]. 
The goal of this research is to consider where to optimally and precisely locate shade trees on a residential parcel such that: a) the shading of facade, windows, and doors of home structures is maximized and rooftop shade is minimized; b) the shade from trees to the surrounding structures is considered; and c) spatial optimization is creatively used to find the best tree locations quantitatively in 3-dimentional (3D) environment. The study is limited to the shade coverage provided by trees and does not consider the dynamics of sensible and latent heat flux that occurs through evapotranspiration, diurnal variations in insolation, and seasonality. While limited in scope, we believe this approach provides an effective strategy for maximizing the shade of trees on residential structures. We therefore present a 3D spatial optimization model that identifies optimal tree locations for residential structures by integrating geographic information systems (GIS) with spatial optimization methods to solve this problem as a mathematical model. We demonstrate the method on a residential neighborhood in the greater Phoenix metropolitan area of Arizona, where tree shade coverage, water conservation, and solar energy potential are critical because of the hot and dry conditions.

\section{Literature Review}

The study described here draws upon literature examining residential tree shade and spatial optimization in 3D environment. From the residential tree shade literature, research shows that west and east tree shade outside of house open structures provide the optimal cooling effects and energy reduction on residential homes [25]. The 3D spatial optimization literature guides the research on how to extend the 2-dimentional (2D) maximum coverage location problem into the 3D space [31]. The following sections elaborate on these bodies of work.

\subsection{Impact of tree shade}

Existing research on the impact of tree shade on home structures associates tree shade with energy use savings in a single-family house setting. Larger energy savings, up to $54 \%$ in some studies [27], are found with trees located on the west side of a home, followed by trees on the east or southwest $[24,25]$. These conclusions are similar across different northern hemisphere climate zones where both heating and cooling conditions are considered. For example, Hwang et al. [26] evaluated the tree shade effects from a single tree to a single family house during the cooling and heating season at both northern (Minneapolis and Indianapolis) and lower latitude (Charlotte and Orlando) locations. Using the distance between the tree and the building through eight cardinal (E, S, W, N) and inter-cardinal points (NE, SE, SW, NW), they show that trees on the west and east side of the house provided more energy conservation than those on the south side during the summer followed by the southeast or southwest.

The beneficial relationship between tree shade and energy is well established but there are only general guidelines on tree placement strategies and the optimal number of trees. Tree placement strategies emphasize cardinal direction with precision only specified at the inter-cardinal level [26] and without incorporating the distance from the home structure. This type of information is limited when it is infeasible to plant trees in specific cardinal directions. Furthermore, the distance trees are planted from the house structure, independent of the directionality, can further impact the area tree shade on a facade. Similarly, the number of planted trees is understudied, with most research focusing on the impact of a single tree. The starting point for these issues is research such as Simpson \& McPherson [24], McPherson et al. [25], Calcerano \& Martinelli [28], Huang et al. [32], and Akbari \& Taha [33], who examined shading effects on different tree heights, multiple story buildings, and number of trees. Results 
are consistent with prior research showing optimal tree placement for energy savings is the east and west side of the buildings. These studies offer a broader range of design considerations, but they still do not consider the relationship to neighboring houses, the open features on the building facade, and a potential for rooftop solar panels.

Design considerations for tree placement additionally need to consider the relationship to nearby buildings, additional shade for windows and doors, and rooftop exposure for solar panel installations. There are two considerations for nearby buildings and tree placement. Nearby buildings, depending on distance, can simultaneously provide shade as well as receive shade from target building trees, although little research has examined this dual relationship. Also missing from the literature is tree placement to maximize shade on windows and doors. Windows and doors have less heat-insulation comparing to facades, so shading the windows by trees or other nearby structures will provide significant energy saving to the household comparing to facade [34]. On the other hand, residential building rooftops are the preferred location for photovoltaic solar panels to generate electricity from direct solar radiation, shown in multiple geographic locations [35]. Tree canopy coverage and shade will significantly reduce the photovoltaic efficiency of solar panels [20,21,23].

\subsection{Spatial Optimization in 3D}

A challenge in maximizing shade coverage is that the buildings and trees are 3D objects, where the comparative location of the trees, roof, facade, doors and windows are important components for insolation remediation. Many real world facility location modeling problems have service coverage in the 3D environment such as camera surveillance or Wi-Fi connection services [31,36,37]. Nevertheless, existing facility location modeling problems are mostly abstracted and formulated in the 2D environment, such as the location set covering problem (LSCP) and the maximal covering location problem (MCLP) [38,39]. To manage the 3D space, these 3D coverage problems were simplified into $2 \mathrm{D}$ environment to ease the formulation and solution of the facility location problems [40]. Because of the dimensional simplification, the reliability and accuracy of optimal facility locations were unavoidably lost projecting from a 3D to a $2 \mathrm{D}$ environment.

With the development of 3D computational tools, several attempts have been made to appropriately formulate and solve the facility location modeling problems in the 3D environment [31]. Some of this has taken place through a 2.5D surface, such as digital elevation model (DEM), by using a visibility analysis or viewshed analysis [41]. Goodchild \& Lee [42] utilized visibility analysis to locate the minimum number of viewpoints to observe the entire DEM surface, or to locate a fixed number of viewpoints to maximize the overall visible area on the DEM. This research extended the concept of set-covering problems to the topographic surface, and viewshed analysis was used to derive coverage on the DEM surface rather than the 2D planar surface. However, DEM is not a real 3D surface and the coverage derivation by visibility analysis required extensive computation. These limitations make it difficult to use their method to obtain the optimal coverage in a true 3D environment. To overcome the computational inefficiency, Kim et al. [43] extended Goodchild and Lee's research by only utilizing terrain features (peak, pass and pit) as candidate viewpoints to acquire the maximal coverage with given number of viewpoints. Their method solved the problems faster and overcame the computational difficulty, but they used the same viewshed method to derive the coverage in 2.5D. Murray et al. [44] found optimal security sensor placements in a 3D university environment utilizing the MCLP and the backup coverage location problem with visibility analysis. They considered the 
3D building blocking effects in the coverage derivation process, but the coverage was only derived on the ground surface and did not consider the coverage on campus building facades. Most recently, Bao et al. [45] applied viewshed analysis to derive the watchtower coverage on the DEM, and integrated LSCP and MCLP solutions to determine the optimal watchtower locations for forest fire monitoring. To simplify the coverage representation, they used viweshed analysis to derive coverage on the $2 \mathrm{D}$ raster surface. Although their methods integrate different methods to improve the efficiency of optimizing watchtower location, the coverage representation is still limited in the $2 \mathrm{D}$ rather than $3 \mathrm{D}$. All of the research above demonstrate that visibility analysis or viewshed analysis are useful methods to help derive service coverage in the $2.5 \mathrm{D}$ or $3 \mathrm{D}$ environment. However, none of these existing literature deals with the service coverage on the real 3D objects. This remains as an obvious research opportunity to extend this type of research into 3D environment.

To extend existing facility location modeling analysis into 3D, a range of problems exist such as computational complexity, 3D data availability, problem size, and model complexity. However, the key question is how to extend the 2D service coverage into the $3 \mathrm{D}$ environment. Besides the visibility analysis, several researchers have attempted to solve the facility location problems with 3D coverage in the real 3D space [31,37,46]. Lee [31] introduced a 3D coverage location model of $\mathrm{Wi}-\mathrm{Fi}$ access points in an indoor environment. Euclidean distance in the 3D space was utilized to generate the $3 \mathrm{D}$ volumetric coverage rather than the $2 \mathrm{D}$ circular coverage. The software environment ArcGIS was able to generate demand nodes and candidate facility sites within the 3D representation, calculate 3D Euclidean distance, and visualize solutions in a 3D environment. Commercial optimization software (CPLEX) successfully solved the problem in seconds with no computational difficulty. Lee's research provides a successful example to extend facility location modeling problems by using 3D volumetric coverage in the 3D GIS environment, however, the 3D volumetric coverage was all perfectly sphere shape and did not consider the coverage change by surrounding obstacles. Similar attempts were made by Amriki \& Atrey [37] on bus surveillance system. In their research, they optimized camera locations and orientations in a 3D interior bus space that was simulated by Autodesk 3ds Max. Maximal overall surveillance coverage with a specific number of cameras and minimum number of cameras to reach specified coverage in the bus were presented. They were able to evaluate the camera's visible region in 3D while avoiding obstacles, but they evaluated the empty space rather than coverage on 3D objects. Zhao et al. [47] demonstrated a simple version of shade coverage optimization for the single family household in Tempe, AZ. Shade coverage was derived on different 3D building structures in the 3D environment. Zhao et al.'s research provides limited details about formulating and solving the facility location modelling problems in $3 \mathrm{D}$, requiring more detailed research on service coverage in $3 \mathrm{D}$ objects and decide the best facility locations.

\section{Methods}

\subsection{Study Area}

The study focuses on a parcel with a detached single-family home and the surrounding buildings within a residential neighborhood in the City of Tempe, Arizona $\left(33.4^{\circ} \mathrm{N}, 111.9^{\circ} \mathrm{W}\right.$, Figure 1). Tempe is a municipality within the greater Phoenix metropolitan area in the Sonoran Desert of the U.S. Southwest. The population of Tempe in 2010 was more than 160,000 with greater than $40 \%$ of the residents living in single-family detached dwellings [48]. With 
summertime temperatures reaching or exceeding $43^{\circ} \mathrm{C}$, heat mitigation strategies such as tree shade are essential for reducing heat-related diseases and energy consumption.

The specific parcel we analyzed is a generic residential parcel in a Tempe residential neighborhood where most of the single-family households were built during the 1950 s and 1960s. The average parcel size is $695 \mathrm{~m}^{2}$ and the typical home is single story with an average size of $134 \mathrm{~m}^{2}$. The residential neighborhood has a dense building arrangement with neighboring structures next to one another on the west and east side, except those close to the major roads running north-south. This specific neighborhood layout makes it infeasible to plant trees on the west or east side of the building to provide shade. Although there are no regulations that specify the type of landscaping, $95 \%$ of the parcels in this neighborhood contain trees (identified from remotely sensed images), which offer some level of shade on the home structures.

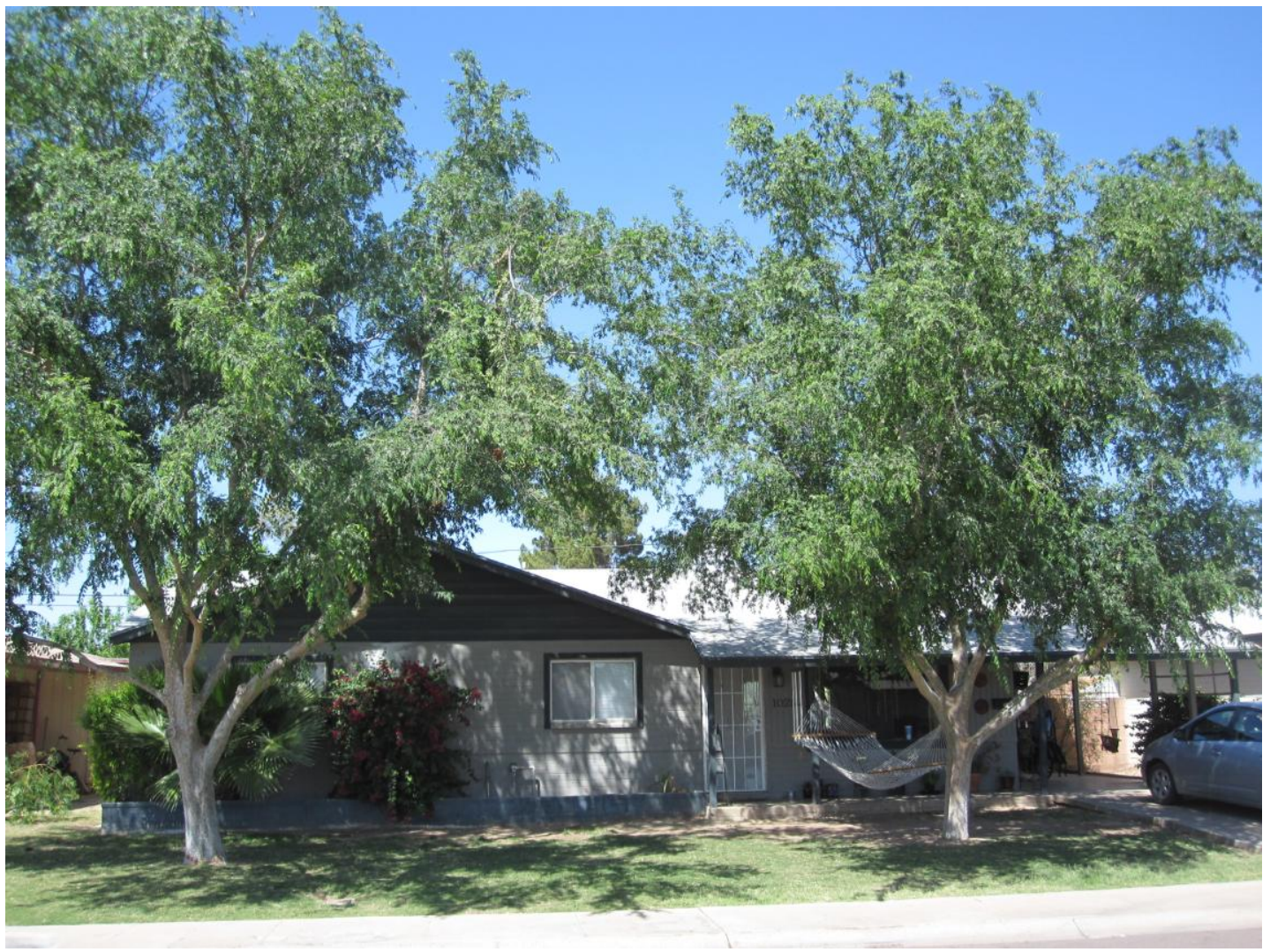

Figure 1. Sample home and parcel in the residential neighborhood of Tempe.

\subsection{Data Sources}

Two data types are required for the analysis, the specifications of the building (e.g., dimensions, location, and facade features) and the specifications of the tree (e.g., tree height, location). The digital representation of the house structure for the selected parcel involves knowing the building size, shape, roof contour, windows/doors locations, and overall orientation. We used Sketchup and its Google Map component to create single family houses at the specific geographical location (Figure 2). We constructed a $18 \mathrm{~m} \times 12 \mathrm{~m}$ house, approximately $216 \mathrm{~m}^{2}$ in size, with $4 \mathrm{~m}$ height sloped rooftop, three $2 \mathrm{~m} \times 1 \mathrm{~m}$ windows, and a $2 \mathrm{~m} \times 1.5 \mathrm{~m}$ front door on the south facade. The house has a multi-faceted roof surface and is positioned with the front of the house facing the south. The area of south roof, south facade and open structures (3 windows 
and 1 door) are $108.5 \mathrm{~m}^{2}, 45 \mathrm{~m}^{2}$ and $9 \mathrm{~m}^{2}$. The distance between this structure and nearby buildings is $3 \mathrm{~m}$.

The digital representation of the tree includes tree size, shape, and position. The 3D tree plugin in Sketchup was used to create a theoretical $7 \mathrm{~m}$ high, $6 \mathrm{~m}$ crown diameter, and $3 \mathrm{~m}$ trunk height to represent a thornless mature mesquite (Prosopis thornless hybrid 'AZT'M'), a common xeriscape flora found in Tempe residential neighborhoods. The advantage of our tree model is that we can represent realistic desert trees with low leaf/area index rather than other simple "cylinder-like" or "cone-like" tree models. By using this tree model, we can derive a more accurate tree shade on the structure. Although different tree shapes, sizes, species can be selected and these parameters would definitely influence the level of tree shade on different building structures such as rooftops, this $7 \mathrm{~m}$ thornless mesquite is typical of those found in Tempe [49,50] (see Figure 2). The challenge, of course, is identifying the best placement of one or more trees to provide shade coverage to this building structure.

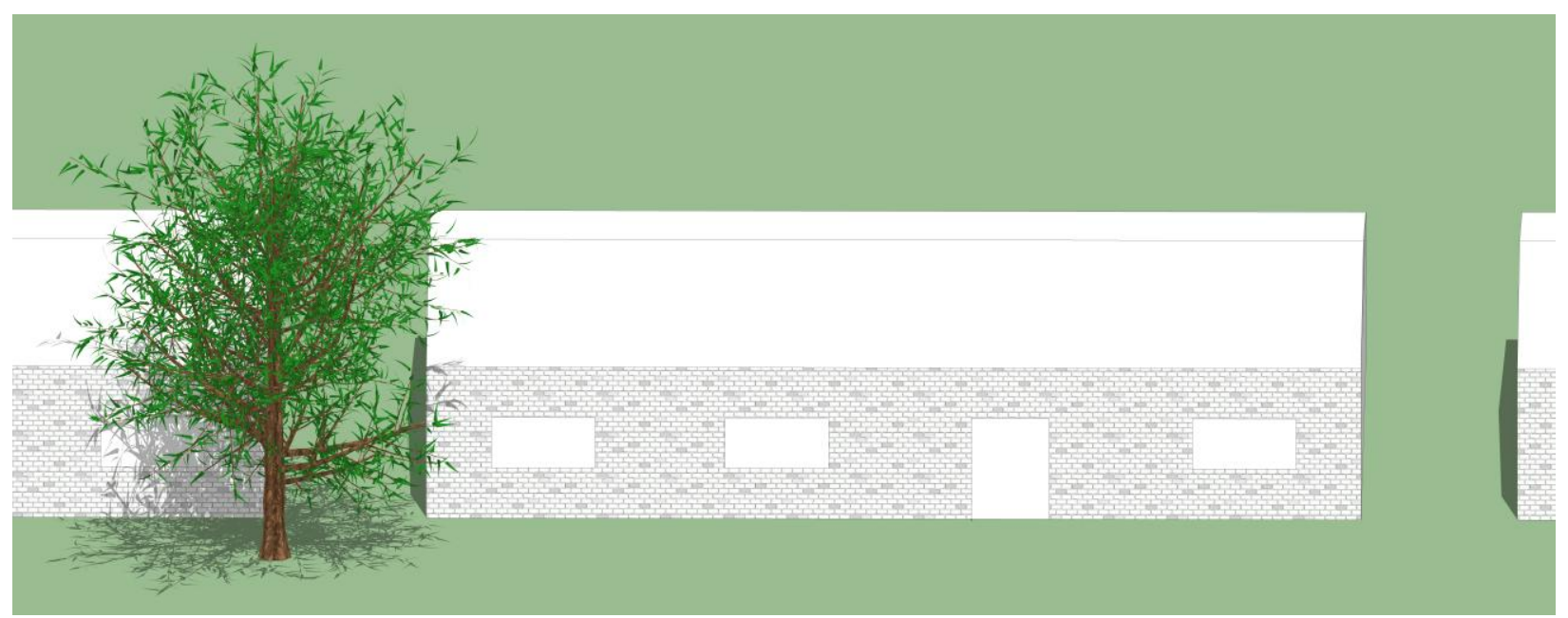

Figure 2. 3D building and tree models.

\subsection{Modeling Approach}

We utilized GIS and spatial optimization to model the tree shade coverage optimization problem. GIS tools provide data storage, spatial analysis, and 3D topology. Optimization methods are used to abstract the real world situation as a mathematical problem as well as solve this problem. This section describes the analytical procedures we used.

\subsubsection{GIS: surface coverage derivation}

Spatial topology and trigonometry principles are used to store the spatial information and to derive surface coverage. Topological data structures in GIS store the location, configuration, and attribute information of 2D and 3D objects. More specifically, to derive the shadow location, trigonometry principles are used. The formal trigonometry specifications are shown in equation (1) - (4). In these equations, $(x, y, z)$ represents points from a tree, $\varepsilon$ is the solar profile angle, $\gamma$ is the difference between solar azimuth and surface azimuth angles, $\beta$ is the solar altitude angle, and $\mathrm{H}$ is the height of the roof. All solar angles are calculated based on Duffie and Beckman (2013) [51]. Figure 3 shows that it is possible to mathematically derive shade coverage associated with 3D object across a range of conditions. Figure 3(a) shows the solar angles and 
1 ground shading, the shading point on the ground is at $\left(x^{\prime}, y^{\prime}, 0\right)$. Figure 3(b) represents the 2 facade shading, the shading point on the facade is $\left(0, y^{\prime \prime}, z^{\prime \prime}\right)$. Figure 3(c) explains the roof 3 shading, the shading point on the rooftop is $\left(x^{\prime \prime \prime}, y^{\prime \prime \prime}, H\right)$.

$$
\mathrm{h}=\frac{\mathrm{z}}{\tan \beta}
$$

where $\mathrm{h}$ is the shadow length on the $2 \mathrm{D}$ plane by solar altitude angle $(\beta)$

$$
\mathrm{x}^{\prime}=\mathrm{x}-\frac{\mathrm{z}}{\tan \varepsilon} ; \quad \mathrm{y}^{\prime}=\mathrm{y}-\mathrm{h} \sin \gamma
$$

which calculates the horizontal shadow projection $\left(x^{\prime}, y^{\prime}\right)$ based on solar profile angle $(\varepsilon)$ and azimuth angle $(\gamma)$

$$
\mathrm{y}^{\prime \prime}=\mathrm{y}-\mathrm{xtan} \gamma ; \quad \mathrm{z}^{\prime \prime}=\frac{\mathrm{x}^{\prime} \mathrm{z}}{\mathrm{x}^{\prime}-\mathrm{x}}
$$

which determines the vertical shadow projection, $\left(\mathrm{y}^{\prime \prime}, \mathrm{z}^{\prime \prime}\right)$, over a house facade according to horizontal shadow $\left(\mathrm{x}^{\prime}\right)$ and azimuth angle $(\gamma)$

$$
\mathrm{x}^{\prime \prime \prime}=\mathrm{x}-\frac{\mathrm{z}-\mathrm{H}}{\tan \varepsilon} ; \quad \mathrm{y}^{\prime \prime \prime}=\mathrm{y}-\left(\mathrm{x}-\mathrm{x}^{\prime \prime \prime}\right) \tan \gamma
$$

which derives the horizontal projection $\left(\mathrm{x}^{\prime \prime \prime}, \mathrm{y}^{\prime \prime \prime}\right)$ on a roof given building height $(\mathrm{H})$, solar profile angle $(\varepsilon)$ and azimuth angle $(\gamma)$

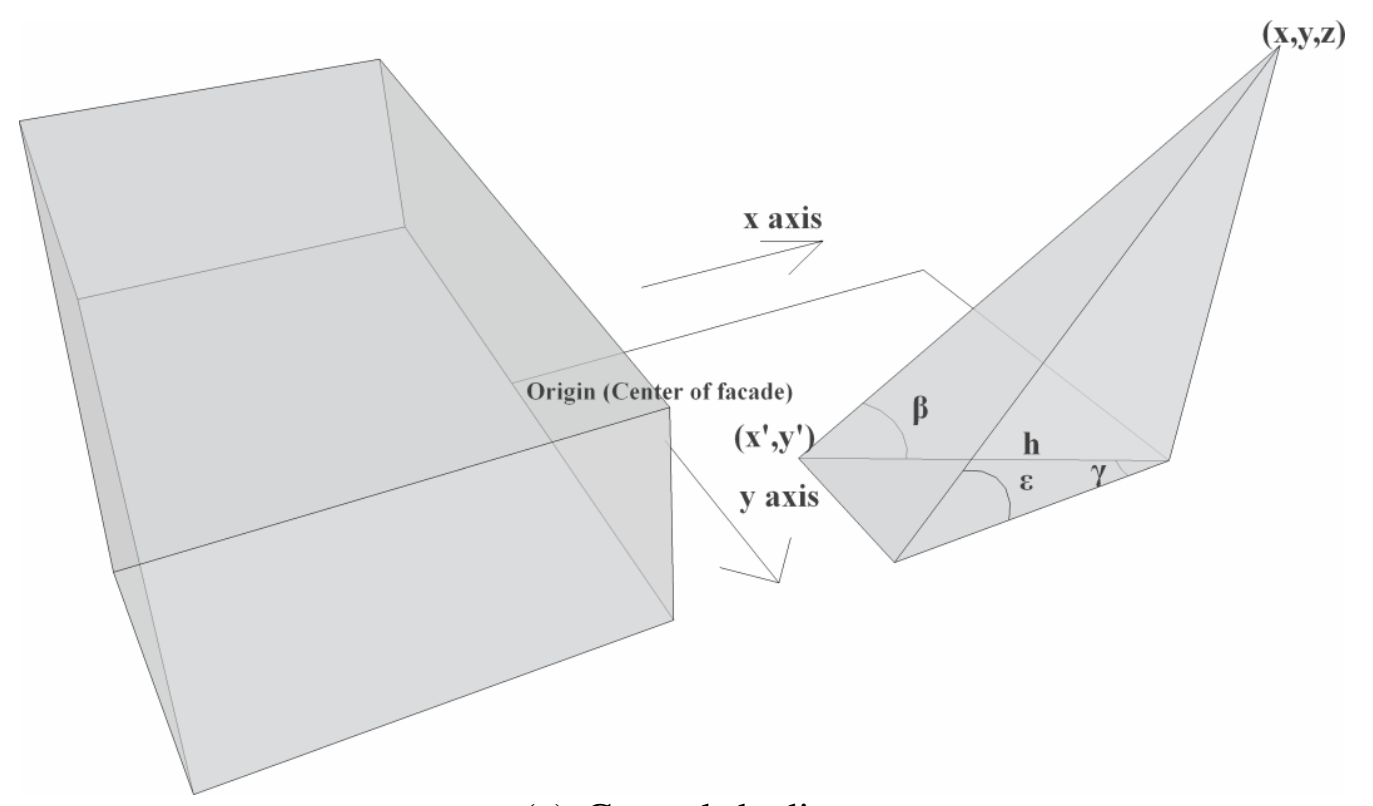

(a) Ground shading. 


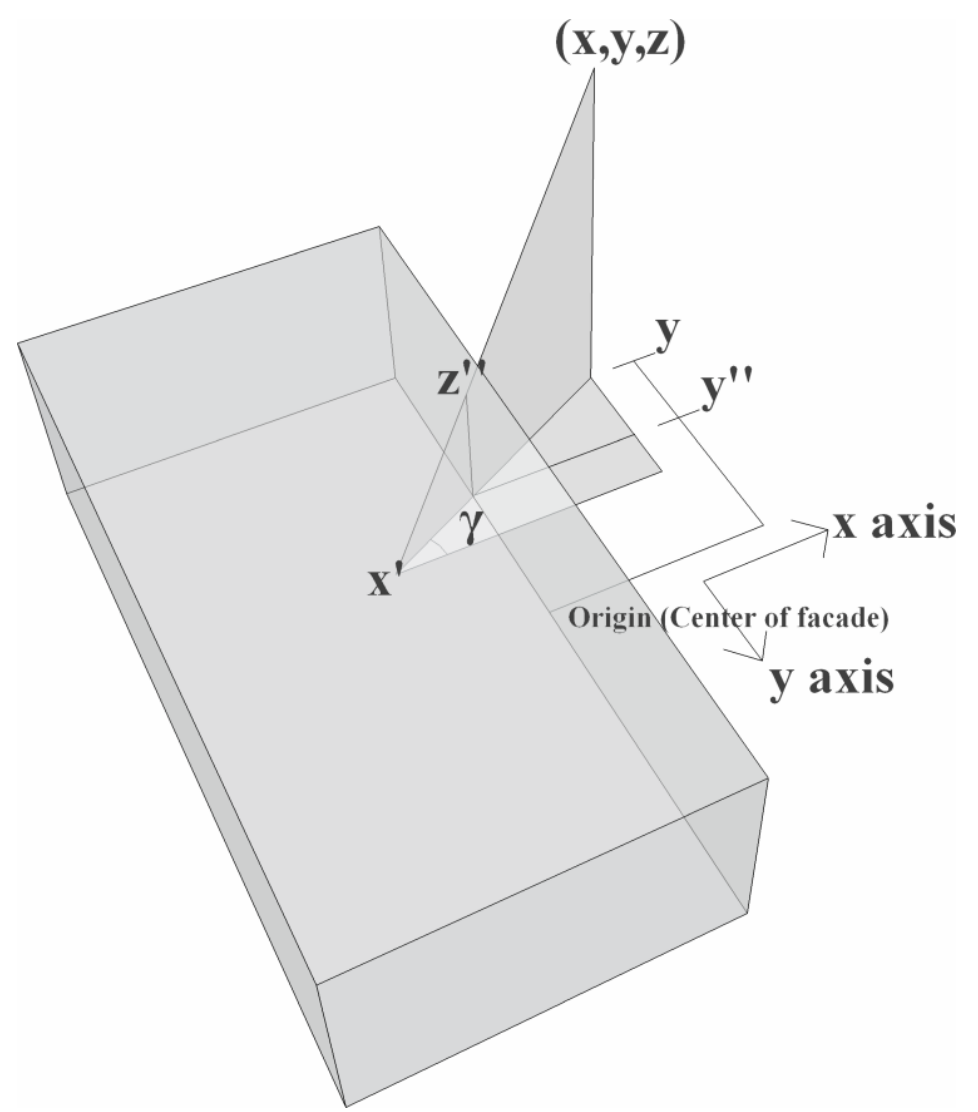

(b) Facade shading.
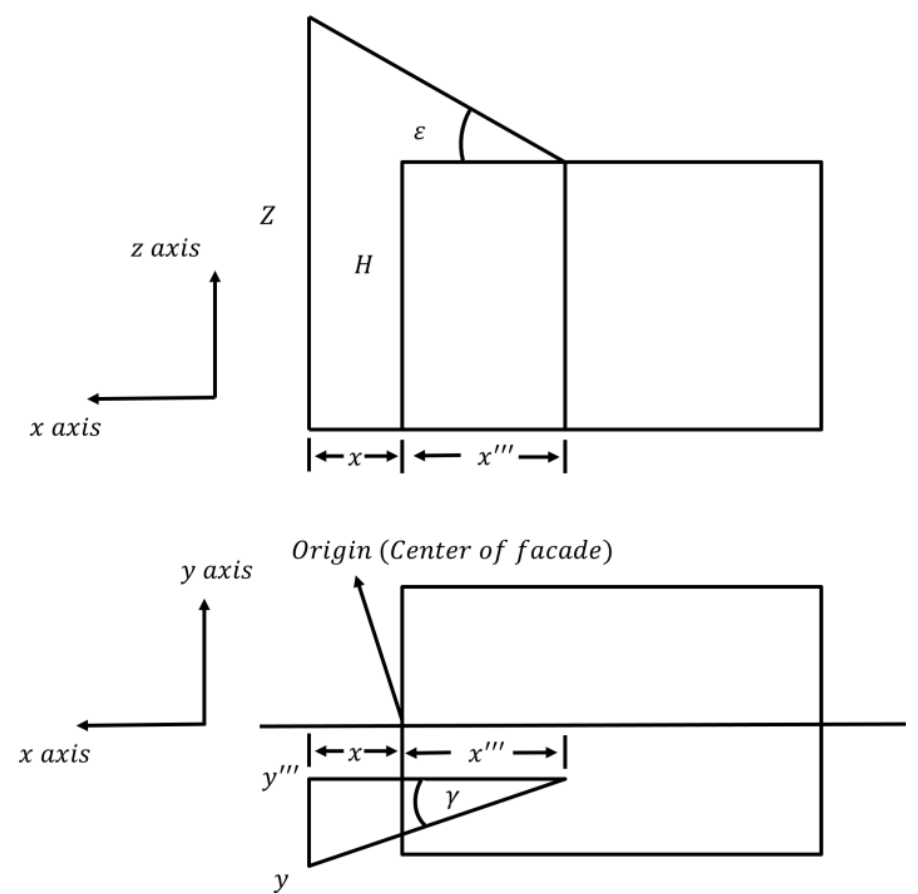

(c) Roof shading.

Figure 3. Shade projections from a point $(\mathrm{x}, \mathrm{y}, \mathrm{z})$ on a 3D object (redraw from Gomez-Munoz et al. (2010) [30]). 


\subsubsection{Spatial Optimization: tree placement}

Using Church \& Murray [52] and the MCLP of Church \& ReVelle [39], we define the following notation:

$\mathrm{i}=$ index of $3 \mathrm{D}$ object components;

$\mathrm{j}=$ index of potential tree locations;

$\mathrm{d}=$ index of extreme heat days;

$\mathrm{t}=$ index of extreme heat hours in a day $\mathrm{d}$;

$\mathrm{w}_{\mathrm{i}}=$ weight of object component $\mathrm{i}$;

$\mathrm{g}_{\mathrm{i}}=$ area of object component $\mathrm{i}$;

$\mathrm{p}=$ number of trees to be located;

$\mathrm{f}(\quad)$ = shade coverage function relating parameters of an object using trigonometry equation (1) - (4);

$\mathrm{S}_{\mathrm{td}}=$ solar angles at time $\mathrm{t}$ on day $\mathrm{d}$;

$\mathrm{N}_{\mathrm{i}}=$ set of potential tree siting locations that shade object component $\mathrm{i}$;

Decision variables are:

$X_{j}= \begin{cases}1, & \text { if tree located at potential site } \mathrm{j} \\ 0, & \text { otherwise }\end{cases}$

$\mathrm{C}_{\text {itd }}=$ amount of object component $\mathrm{i}$ covered at time $\mathrm{t}$, day $\mathrm{d}$;

This notation allows for the specification of object components, such as roof, facade, windows and doors. Accordingly, $\mathrm{C}_{\mathrm{itd}}$ tracks shade provided to object component $\mathrm{i}$ at time $\mathrm{t}$ on day $\mathrm{d}$ as a function of surface coverage. Using this notation, the model for $3 \mathrm{D}$ object coverage is as follows:

Maximize

Subject to:

$$
\begin{gathered}
\sum_{\mathrm{i}} \mathrm{w}_{\mathrm{i}} \sum_{\mathrm{d}} \sum_{\mathrm{t}} \mathrm{C}_{\mathrm{itd}} \\
\mathrm{C}_{\mathrm{itd}}=\mathrm{f}\left(\mathrm{g}_{\mathrm{i}}, \mathrm{S}_{\mathrm{td}}, \mathrm{X}_{\mathrm{j}}, \mathrm{j} \in \mathrm{N}_{\mathrm{i}}\right) \forall \mathrm{i}, \mathrm{t}, \mathrm{d} \\
\sum_{\mathrm{j}} \mathrm{X}_{\mathrm{j}}=\mathrm{p} \\
\mathrm{X}_{\mathrm{j}}=\{0,1\} \forall \mathrm{j} \\
\mathrm{C}_{\mathrm{itd}} \geq 0 \forall \mathrm{i}, \mathrm{t}, \mathrm{d}
\end{gathered}
$$

The objective, (5), is to maximize tree shade coverage of different object component i (roof, facade and windows/doors) during a particular time period and date with a predefined weight $\mathrm{w}_{\mathrm{i}} . \mathrm{w}_{\mathrm{i}}$ represents the priority of tree shade coverage to different building structure i. In general, windows/doors are open structures and need the most shade to mitigate direct solar radiation in the desert environment, following with building facade. Roof needs less or no shading because residential roof is always built with heat-insulation materials and is a perfect place to install solar panels to generate electricity from solar energy. Constraints (6) define the amount of coverage that will be provided to object component i (roof, facade and windows/doors) based upon the tree locations and solar angles at a specific time period and date. Constraints (7) specify the number of trees to be located. Integer restrictions on the siting variables are stipulated in Constraints (8). Non-negative restrictions on coverage variables are indicated in Constraints (9). 
We solve the 3D tree shade optimization problem through a heuristic solution approach for three reasons. First, it is computationally intensive to calculate shade coverage on different building structures by trigonometry principles we mention above, especially when we have a detailed and complicated 3D tree and building models. Second, there is not an exact method that can be applied to solve this optimization problem with a nonlinear constraint involving a trigonometric function. Third, trees can be located anywhere in the continuous space resulting in infinite combinations of different tree arrangements with multiple trees. Thus, we used a greedy-adding algorithm combining with brute-force (enumeration of all possible candidate sites) method to find a near-optimal solution for this problem. The detailed steps are:

1) Define the set of potential tree siting locations $\left(\mathrm{N}_{\mathrm{i}}\right)$ based on tree height, tree crown diameter, outdoor landscaping codebook, and building layouts.

2) Brute-force method is used to locate the first tree by enumerating all the potential tree locations around the building during heat hours at given number of summer days. The best tree location can be found by maximizing tree shade coverage $\left(\mathrm{C}_{\mathrm{itd}}\right)$ on building structures with predefined shading weights $\left(\mathrm{w}_{\mathrm{i}}\right)$.

3) To avoid tree crown overlap, the potential tree siting locations $\left(\mathrm{N}_{\mathrm{i}}\right)$ within the existing tree crown is eliminated.

4) Repeat step 2) and 3) to locate the next tree around the building, until the potential tree siting location set is empty or locates $\mathrm{p}$ trees.

\subsubsection{Model parameter explanation and simplification}

Because infinite potential tree locations exist, the simplification of potential tree siting location set is necessary. Potential tree placement on the residential parcel is summarized based on landscape design guidelines [53,54]. In the northern hemisphere, landscape design guidelines suggest that trees should be planted on the south, west, or east of structures. Because of the space limitation on the west and east side of the house, we limited tree placement to the south of the building. Further, to avoid unnecessary tree shade coverage on the rooftops, a minimum distance of $3 \mathrm{~m}$ between the tree and the building is predefined (Figure 4).

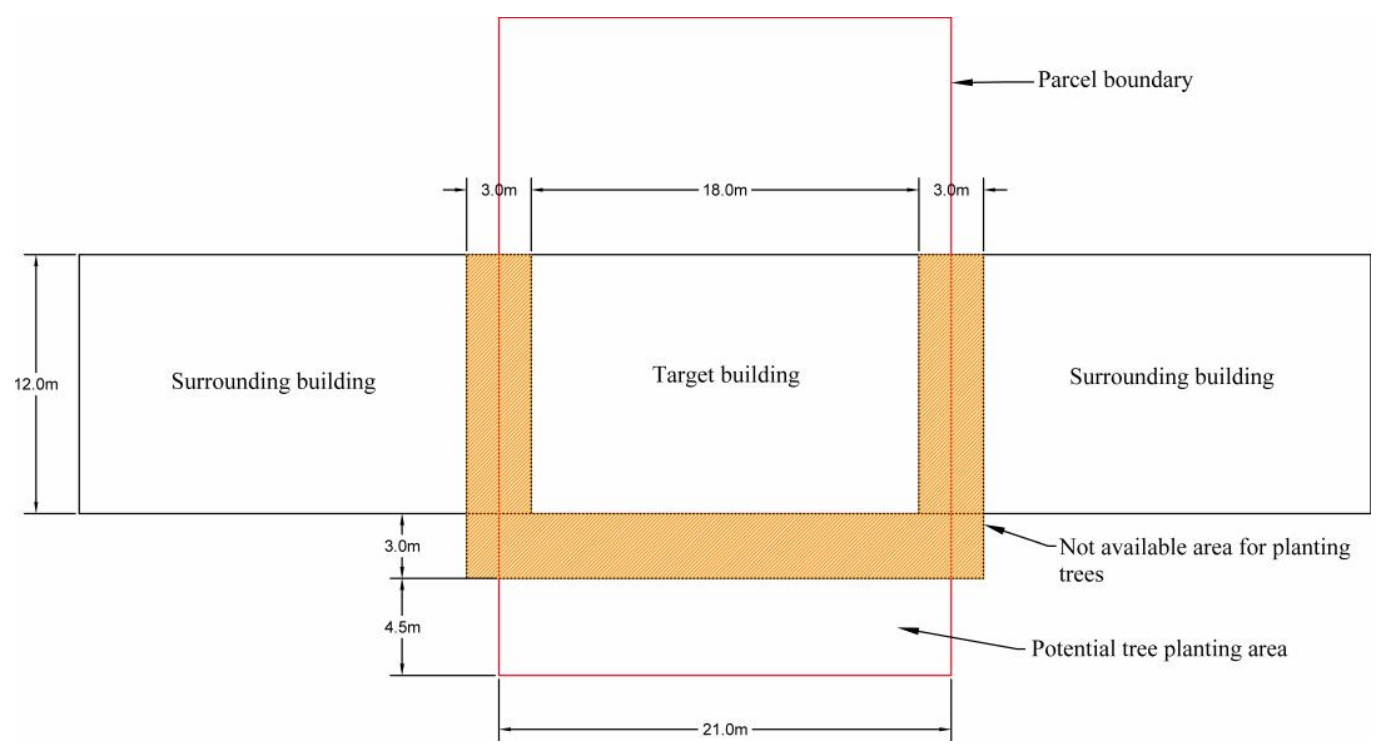


To simplify the solution process, the continuous space was discretized into 42 potential tree locations as the potential facility location set $\left(\mathrm{N}_{\mathrm{i}}\right)(3 \mathrm{~m}$ intervals in the east-west direction and 1 $m$ intervals in the south-north direction). Figure 5 shows half of the potential tree locations in the study site. Besides testing the shading benefits for the target building, we also derive the shade coverage on the two nearby buildings to obtain the shading benefits for the surrounding building structures. We locate two trees $(\mathrm{p}=2)$ because this is the most common number of trees to be planted in the desert city considering the water usage and landscape regulation, but in general, the spatial optimization method can be used to locate any number of trees in the 3D environment.

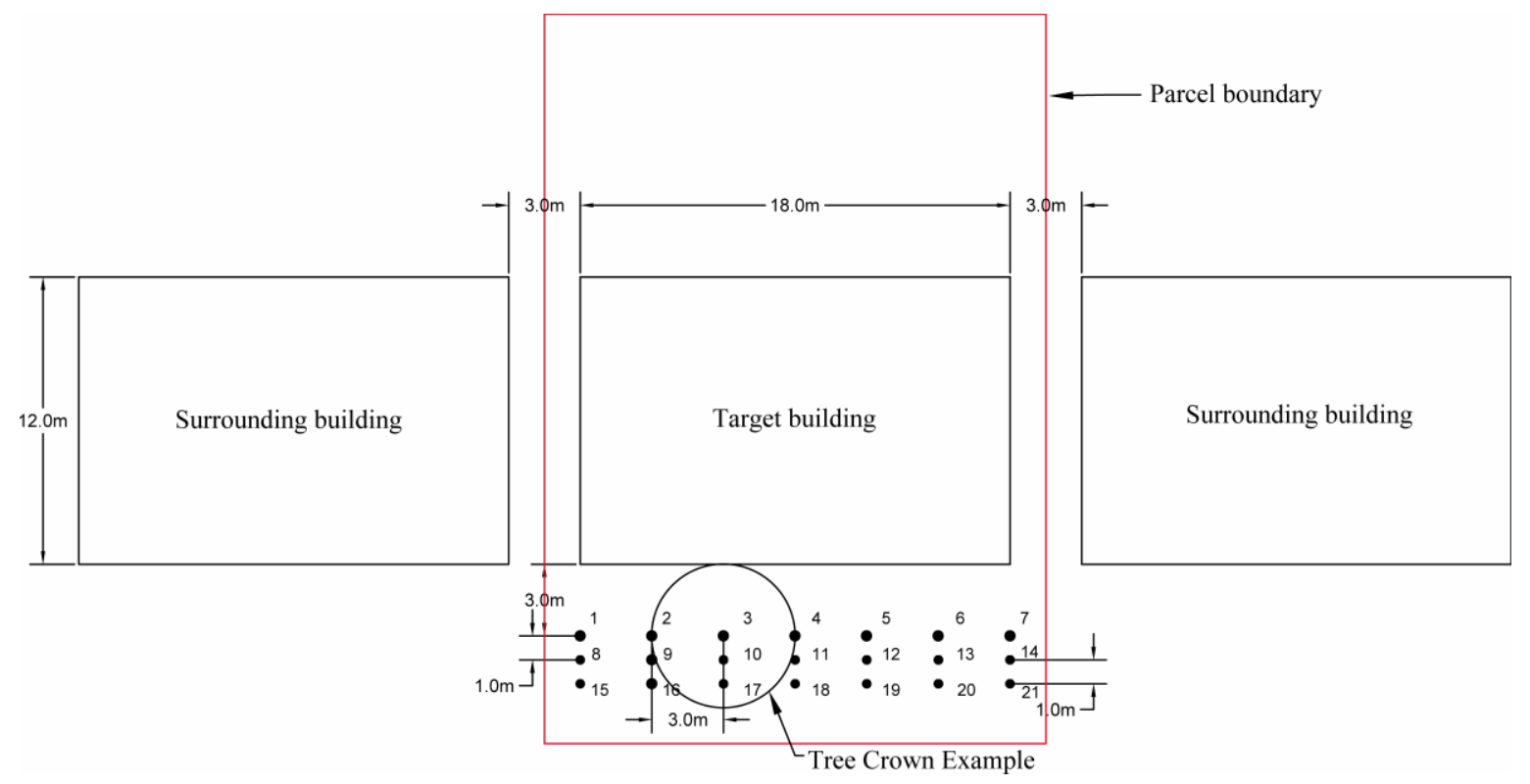

Figure 5. Potential tree locations in the study site (Plan view).

The weight of object component $\mathrm{i}\left(\mathrm{w}_{\mathrm{i}}\right)$ was defined as $0.7,0.4$ and -0.1 for windows/doors, facade and rooftops. Several reasons helped to define these weighting coefficients. The structure components we assigned as most important for shading were open structures such as windows and doors. Although these open structures are a small area compared to facades and rooftops, solar radiation impacts are greatest through windows and doors [55]. From existing literature, the heat conduction from the sun through $1 \mathrm{ft}^{2}$ of facade or roof was only about $2 \%$ of the heat that passed through a window [56]. Thus, when tree shade covers open structures, there are greater energy savings. Considering heat conduction and solar radiation, shade coverage on windows/doors had the highest priority, followed by facade, and rooftops. Further, residential roof was an appropriate location to place solar panels to generate solar energy. We penalized the rooftop shading by using a small negative weight.

The shade was determined using trigonometry principles detailed in section 3.3.1. Sun location and radiation was simulated in Sketchup. The criteria for measuring shade effects on different structures of a single-family residence are based on the work of Shaviv \& Yezioro [57], who proposed the use of a geometrical shading coefficient to express the ratio between shaded and total examined surface areas. We selected the heat period from 9:30 to 15:30 in a 30 minutes' interval during four heat days (June $15^{\text {th }}$, July $15^{\text {th }}$, August $15^{\text {th }}$, and September 15th) to represent the periods of greatest insolation [58]. To simplify the optimization criterion, we 
structures in this research. A heuristic approach for solving the optimization model, (5) - (9), was structured based on the section 3.3.3. The accumulated weighted shaded area, objective (5), was calculated for each potential location with the given weights $\left(\mathrm{w}_{\mathrm{i}}\right)$ for windows/doors, facade and rooftops.

\section{Results}

The optimization results illustrate how tree shade area changes across different locations and building-tree distances (Figure 6). From Figure 6(a), tree shade coverage significantly decreases when we increase the distance between the tree and the building, and the central parts of the front yard will provide the most shade for the overall household in regardless of building-tree distance. Figure 6(b) shows the tree shade coverage surface in the potential tree planting area by interpolation in the GIS environment. The results show that facade tree shade area could be reduced to zero if trees are planted near the southern parcel boundary and far away from the buildings. This demonstrates that simply following the guidelines, planting trees on a specific side of a buildings, could result in little or no shade on the house structure.

\section{Accumulated Weighted Shaded Area (Distance of 3 m, 4 m and $5 \mathrm{~m}$ from left to right. Unit: $\mathrm{m}^{2}$ )}

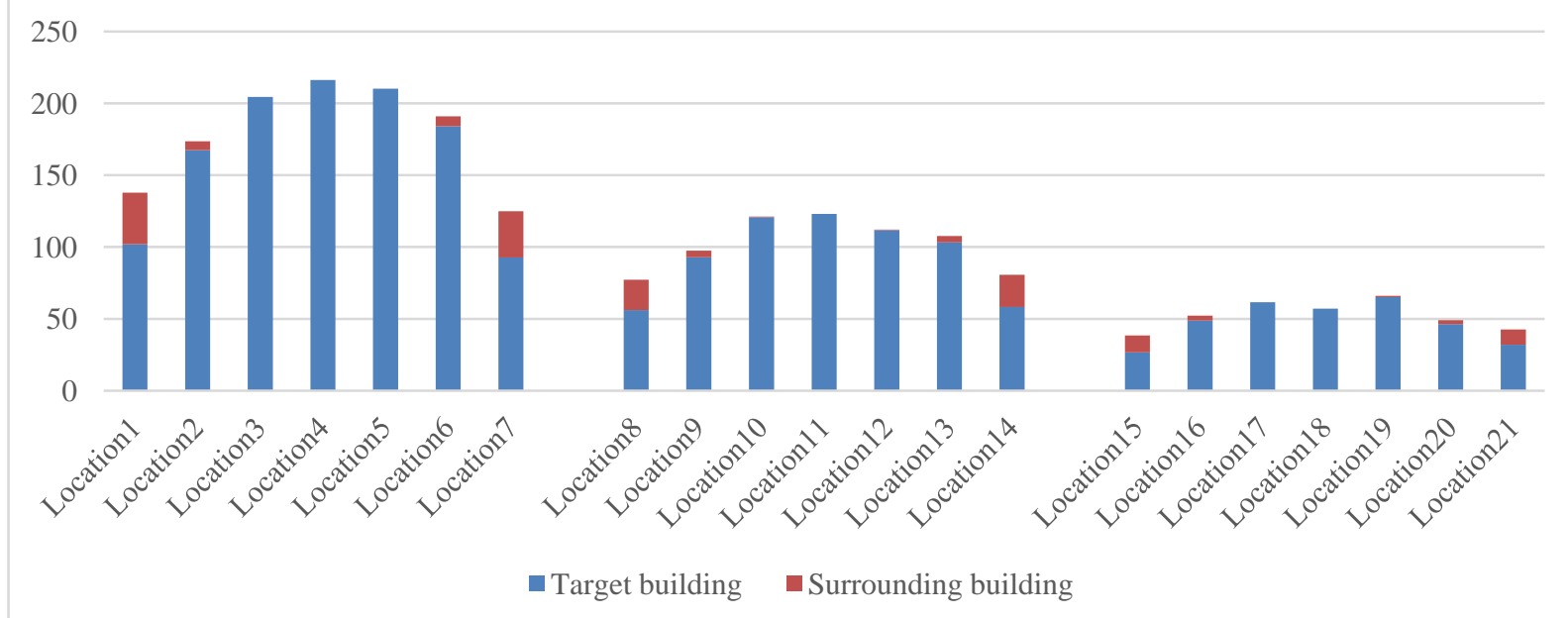

(a) Tree shade coverage under different locations and tree-building distances. 


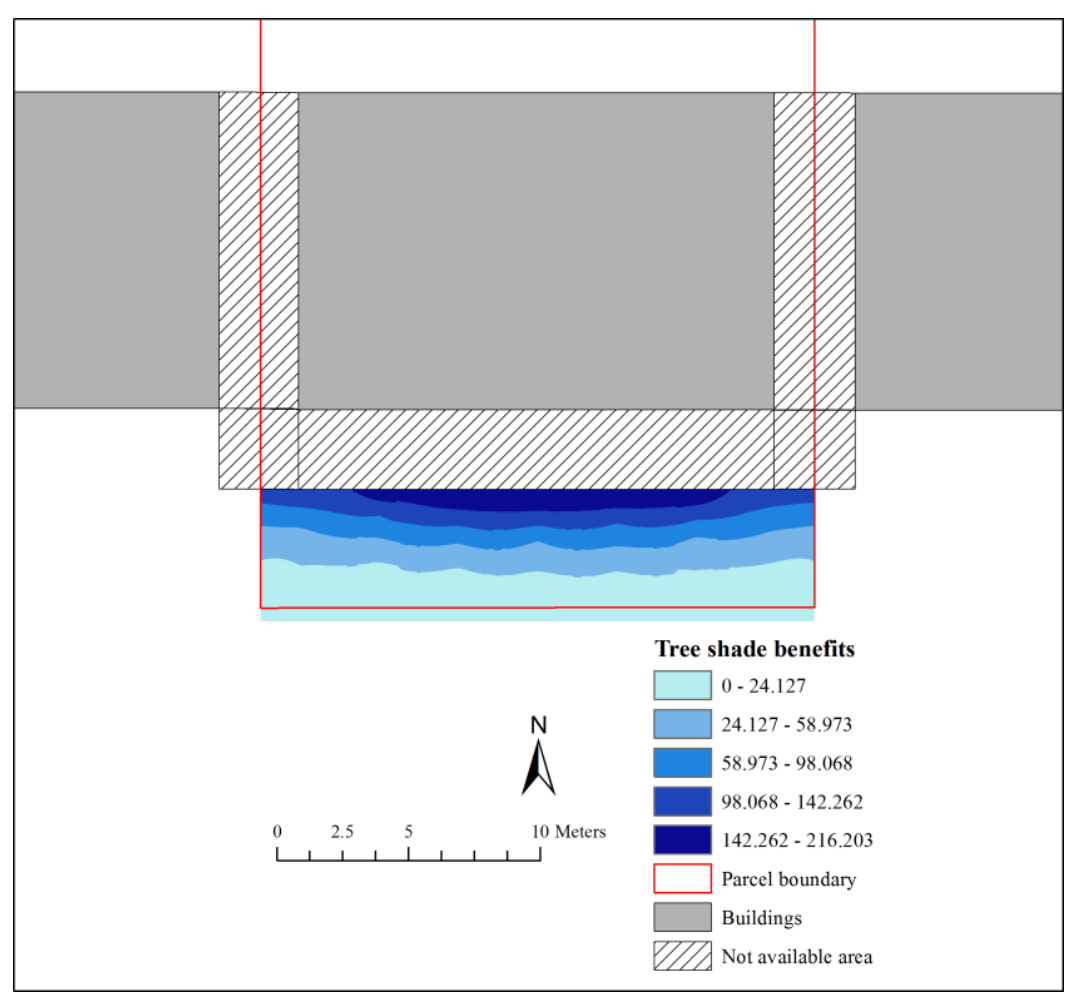

(b) Geographical representation of tree location priority when planting one tree.

Figure 6. Tree shade coverage in one tree scenario.

The results of the heuristic modeling for the first tree show that the best site is at location 4 , which is $3 \mathrm{~m}$ from the building's south facade and $9 \mathrm{~m}$ from the building west and east facades (Figure 6a and 7a). The accumulated shading time from this single mature mesquite tree to the central part of the building south facade and open structures on August $15^{\text {th }}$ is up to four hours (Figure 7b). Results show that the single mature mesquite tree can provide this shading to the central parts of building facade and open structures on this day.

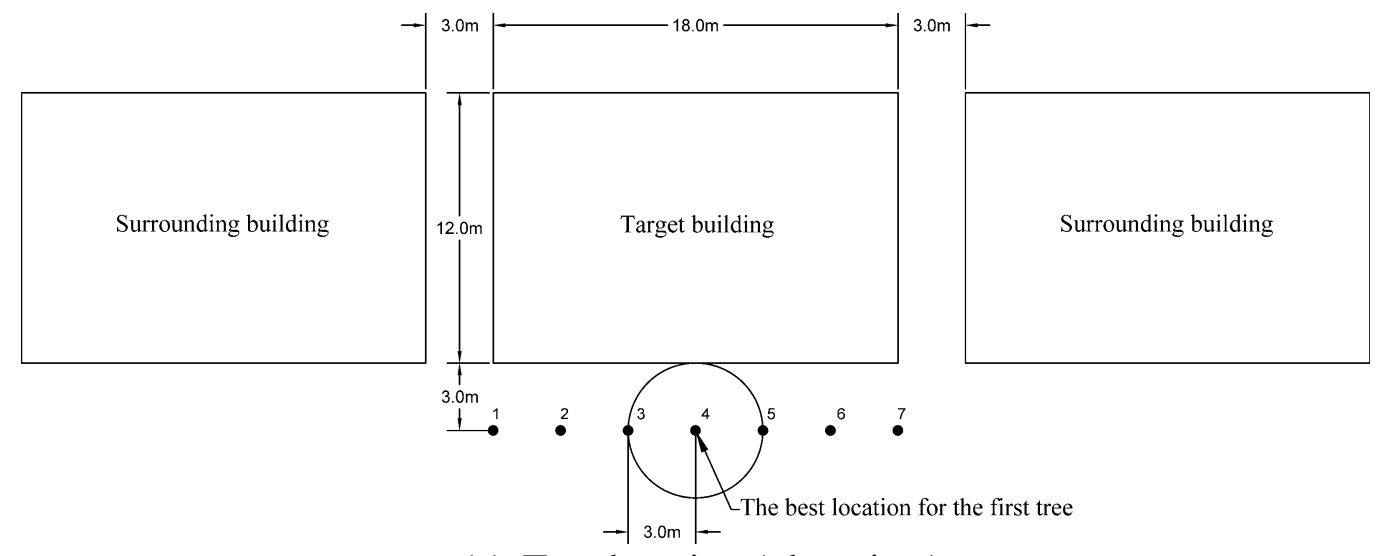

(a) Tree location (plan view). 


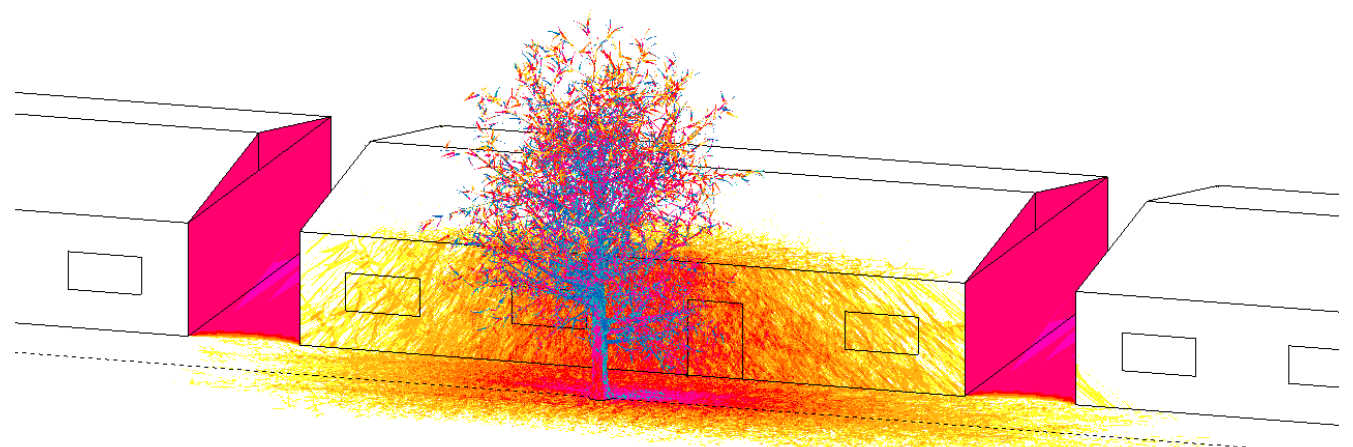

(b) Shading time in 3D environment.

Figure 7. Optimal shading from one tree (August $15^{\text {th }}$, at location 4).

To locate a second tree with our heuristic method, we first eliminated the potential facility set based on the first tree location and landscaping limitation (no tree crown overlap), then enumerate all remaining options. To improve the performance of the heuristic algorithm, we repeated the heuristic algorithm with three different starting conditions (the first tree locates at 3, 4 , or 5). The results show that the best near-optimal solution is at location 3 and 5 (see Figure 8 and Figure 9(a)). The accumulated shading time from these two trees on August $15^{\text {th }}$ is shown in Figure 9(b). Two mature mesquite trees can provide up to 6 hours shading to the central parts of the building south facade and open structures in this day, and provide at least one hour shading to the whole building facade. The top three two-trees siting arrangements are location 3 and 5, location 4 and 6 , and location 2 and 5.

\section{Accumulated Weighted Shaded Area (Unit: $\mathrm{m}^{2}$ )}

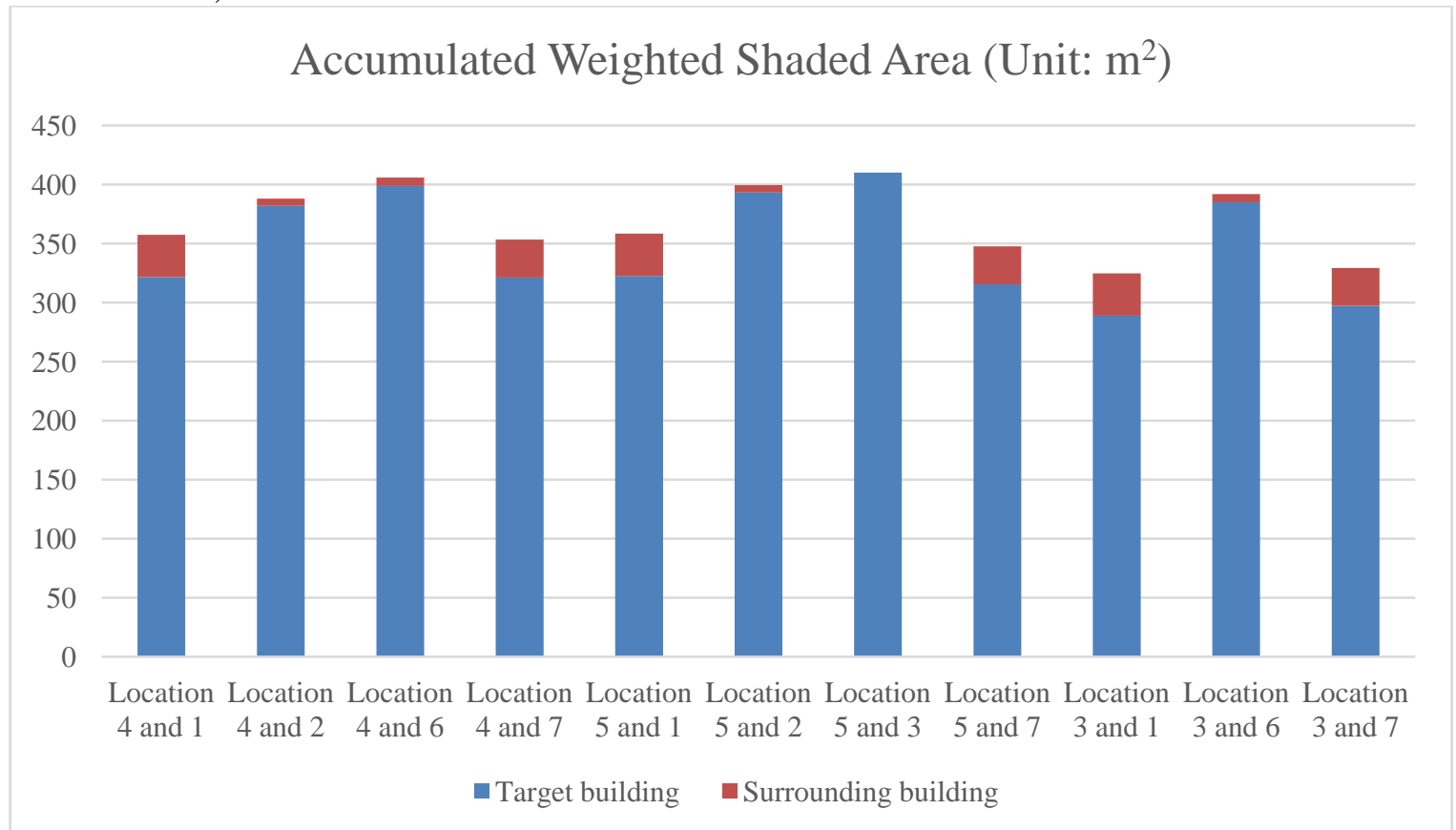

Figure 8. Shading benefits comparison for two trees (only showing the two tree combination from location 1 to 7$)$. 


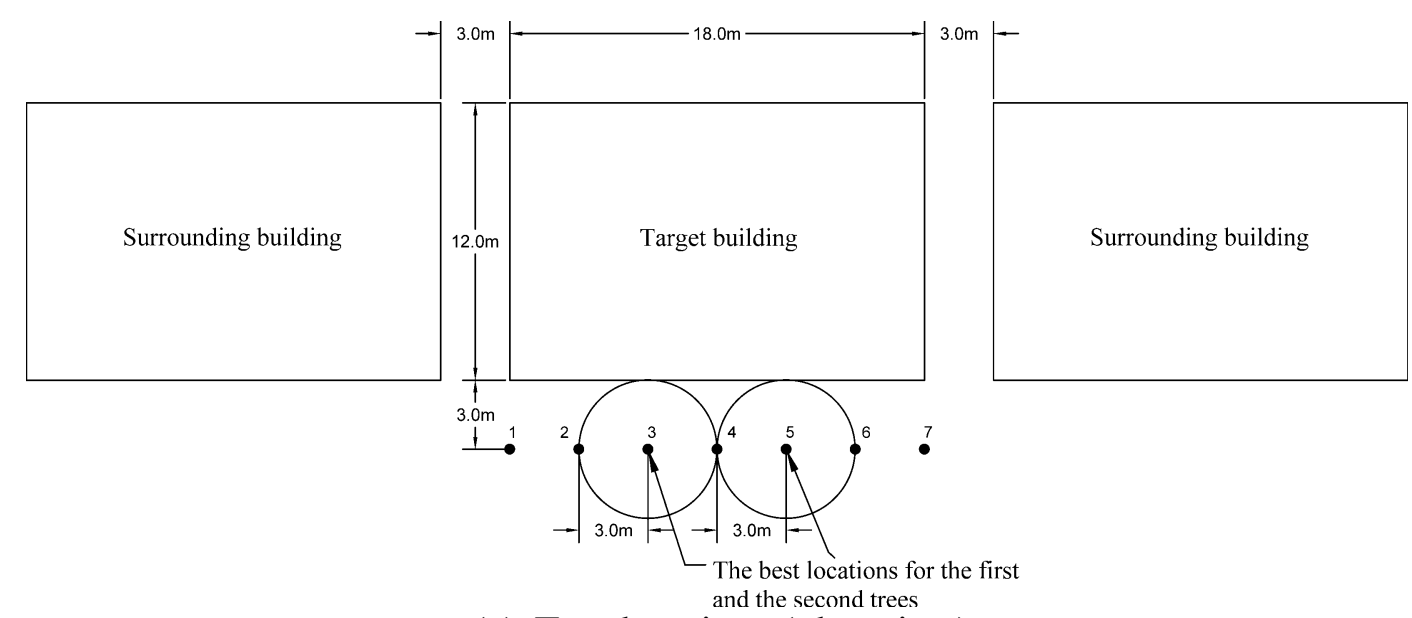

(a) Tree locations (plan view).

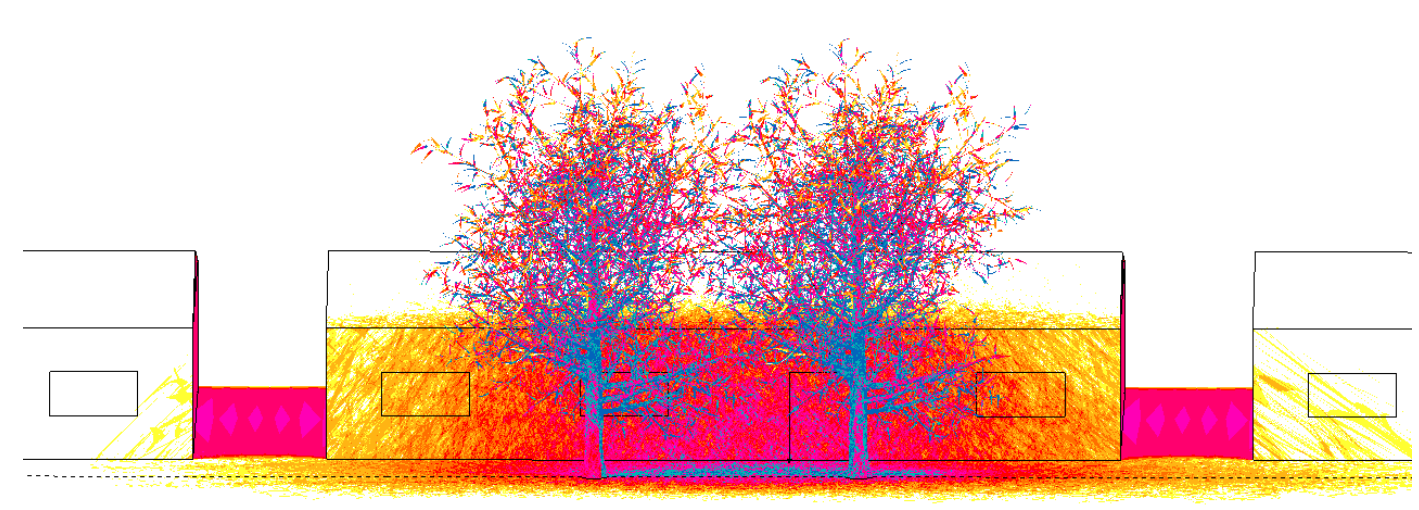

(b) Shading time in 3D environment.

Figure 9. The best near-optimal shading results from two trees (August $15^{\text {th }}$, at location 3 and 5).

A breakdown of component coverage (windows/doors, facade and rooftops) is summarized in Figure 10 for the thirteen 30-minutes time periods between 9:30 and 15:30 with the average value of June $15^{\text {th }}$, July $15^{\text {th }}$, August $15^{\text {th }}$ and September $15^{\text {th }}$ in 2016 . Two trees are located at location 3 and 5, which presents the best near-optimal shading area found by the spatial optimization method in a two-tree setting. In Figure 10(a), the tree shade coverage ratio demonstrates the shade to different components of the residential structures. For example, windows/door had more than 35\% shade coverage ratio during 11:00 to 15:00. This results in a steady solar radiation deduction provided by these two trees for this single family household during the heat hours. The south facade of the house was covered by shade more than $30 \%$ from 10:00 to 15:00. Significant blocking effects for solar radiation from tree shade were provided. With less solar radiation penetrates the open structures and heats up building facade, the individual household can significantly reduce its energy consumption. The south roof coverage ratio was all less than $7 \%$, which represents a good exposed rooftop for the solar energy potential. From Figure 10(b), the four-day average open structure accumulated shade coverage is $41.96 \mathrm{~m}^{2}$, with the maximum coverage of $3.82 \mathrm{~m}^{2}$ out of $9 \mathrm{~m}^{2}$ at $12: 00$. The four-day average accumulated shade coverage is $202.94 \mathrm{~m}^{2}$, with the maximum coverage of $18.38 \mathrm{~m}^{2}$ out of $45 \mathrm{~m}^{2}$ 
1 at 12:00 as well. The four-day average accumulated shade coverage of rooftop is $80.26 \mathrm{~m}^{2}$, with 2 the maximum coverage of $7.03 \mathrm{~m}^{2}$ out of $108.5 \mathrm{~m}^{2}$ at 10:30. By using the spatial optimization 3 method, we successfully maximize the building facade and open structure shading, and minimize 4 the shade on the building rooftop.

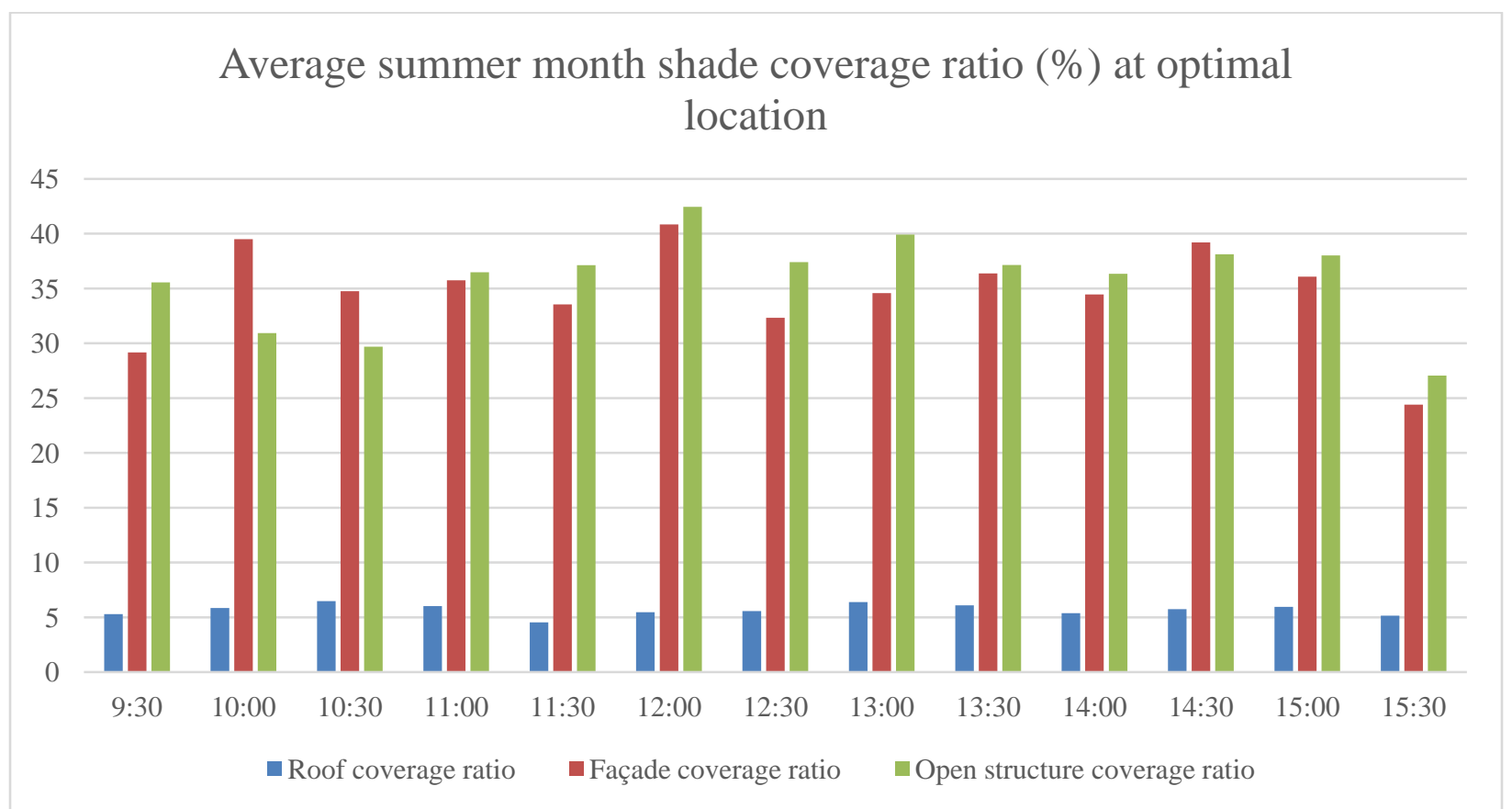

(a) Tree shade coverage ratio.

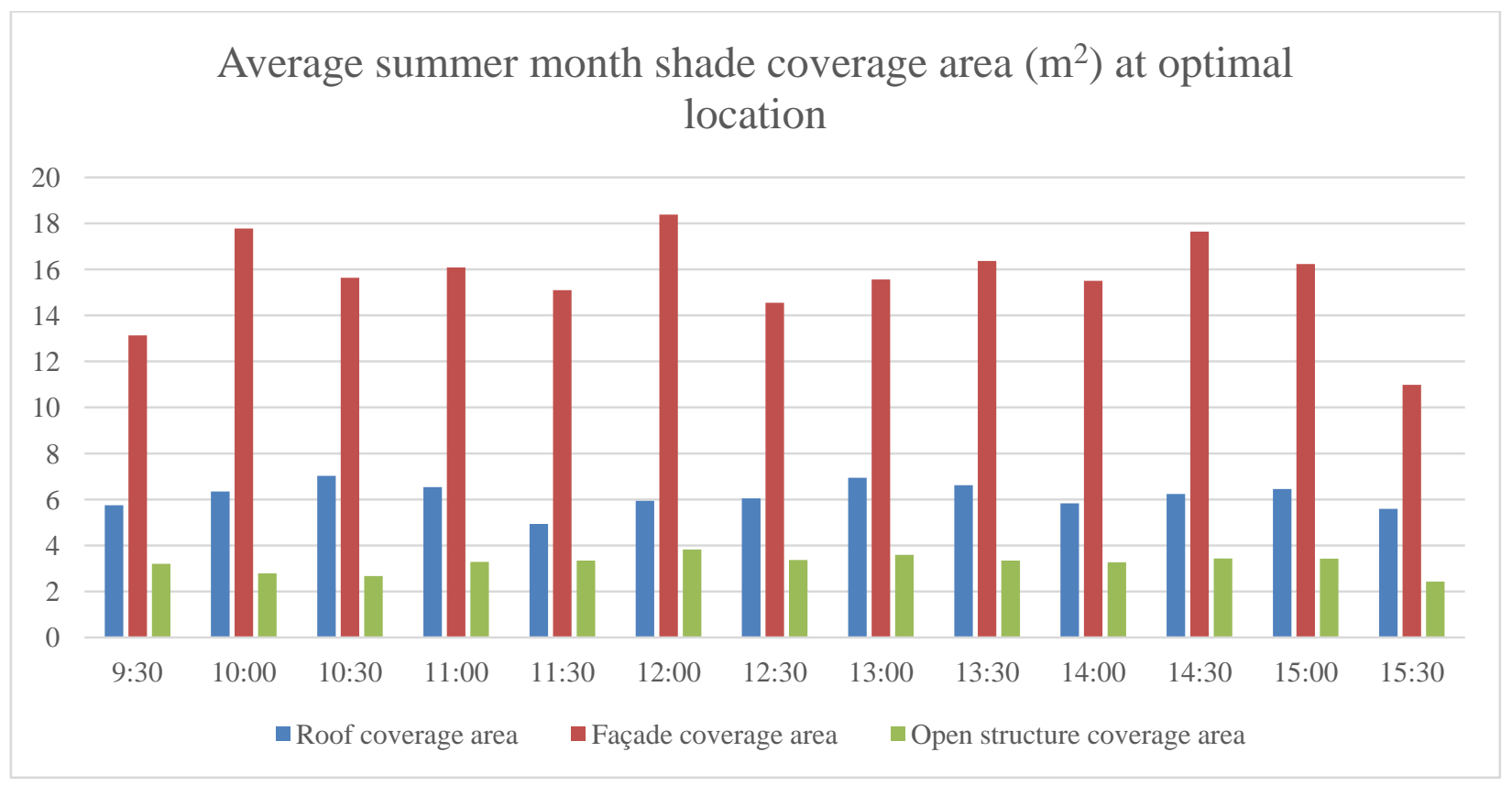

(b) Tree shade coverage area.

11 Figure 10. Tree shade coverage ratio with the best near-optimal arrangement (location 3 and 5). 


\section{Discussion}

This study shows that maximizing shade area occurs with trees planted $3 \mathrm{~m}$ south of central part of the home structure, unlike the results from prior studies that measure energy efficiency or consumption from nearby tree shade. The reason behind this difference is that the compact urban setting restricts residents to plant trees in the west and east side of the household. When locating trees in front of the building south facade, the locations of windows \& doors are significant factor to influence the decision making. With limited number of trees to be planted for each residential household, homeowners should focus more on planting shade trees in the central area of their south front yard to provide shade (30\%-35\% shade coverage with two trees) for their own open structures and facade. Previous research recommend to plant trees at the southwest corner of the building front yard, this research result shows that it is not always optimal to simply plant trees at the southwest side of the buildings. A quantitative method that incorporates neighborhood conditions and building/tree characteristics is a more reliable way to achieve the maximum shade.

The near-optimal two-tree arrangement (location 3 and 5) provides around $35 \%$ shade coverage of open structures and facades during the peak heat hours at summer months. Since most of the previous literature did not recommend to plant trees on the south side of buildings (limited shade coverage during the summer), the results demonstrate that two desert trees at optimal locations can still provide a significant amount of shading residential household. To consider the aesthetic design and add the landscaping variety of residential trees, different tree spacing can be adapted in the residential yard based on the results in Figure 8. Besides the tree arrangement at location 3 and 5, location 4 and 6 or location 2 and 5 also provide significant shade coverage to the residential household.

The breakdown of the building components (windows \& doors, facade, and rooftops) make it possible to maximize tree shade coverage on the "shade-friendly" building structures such as windows \& doors. With the weighting coefficients in the optimization method, the emphasis of tree shade coverage can be easily adjusted depending on different types of building materials and structures. On the other hand, rooftop exposure is preserved by minimizing tree shade coverage on the building rooftops, which is not examined or achieved in the previous tree shade related research. Besides considering the separated building components, tree shade coverage to the surrounding buildings are also evaluated. In this particular compact residential neighborhood, tree shade coverage on the nearby buildings cannot be ignored, especially when planting trees near the parcel boundaries. However, the results show little shade coverage on the surrounding buildings. The reason behind this finding is that shadow length is relatively limited during the greatest insolation hours from 9:30 to 15:30. The shading benefits to the surrounding buildings need to be further explored in the future study.

In addition to the specifics of tree shade, this paper also demonstrates the way in which a 3D spatial optimization model can support the identification of optimal tree locations for providing shade to 3D urban building structures. To implement this model, 3D modeling along with GIS spatial processing techniques are used to determine the three dimensional geometric properties of structures to be shaded by the optimal location of trees. We provide a demonstration and implementation of the model using a single-family house with its surrounding buildings in Tempe, Arizona. GIS and spatial optimization techniques were employed to formalize a mathematical model that could be used for identifying optimal placement of the single tree that optimize accumulated shade coverage on building structures. Heuristic was used to solve the optimization problem involving trigonometry functions and provided the near-optimal solutions 
of the two trees scenario (real world scenario) for policy makers and planners. The optimization results show that two trees can provide a maximum of $244.90 \mathrm{~m}^{2}$ accumulated shade coverage to a single-story residential house's south facade and open structures from 9:30 to 15:30 (shade area was calculated in every 30 minutes) on a hot summer day from June to September, and the maximum shade coverage is achieved at 12:00 with the shade area of $22.20 \mathrm{~m}^{2}$ in the $54 \mathrm{~m}^{2}$ south facade and open structures. Optimal tree locations can offer significant energy savings, reduce long-term economic costs and create a healthier living environment.

This is the first known attempt to identify the precise location and number of trees to maximize tree shade on home structures. There is, however, more that can be done to extend this work. For example, this study only considers an individual single-family household and its surrounding buildings. A large residential region will require automated 3D building extraction and construction techniques combining remote sensing and GIS. Also, different tree species, varying growing processes and alternative tree height and crown size reflect important options for flora. In this research, we use a $7 \mathrm{~m}$ high mature desert tree to represent a common situation in the desert setting, however, different tree species will have different tree height, leaf area index/canopy density, and crown size [59]. Furthermore, all of the tree-related parameters will change during the tree's growing process [60]. All of these factors would influence the final optimization results. Future research can extend this work to focus on comparing tree shade benefits with different tree-related parameters at the same tree locations and arrangements.

\section{Conclusions}

Strategic shade provision offers the potential to mitigate the effects of high solar radiation loads on summer days, enabling economic, environmental and health related benefits. We build upon research that links tree coverage with energy savings with higher levels of precision on tree placement. Unlike prior research, we provide specificity beyond the cardinal direction and address the relationship to nearby structures, shade on windows and doors, and retaining the option for rooftop solar panels. Future directions involve evaluating the microclimate benefits under different tree locations and arrangements, such as wind speed/direction and solar radiation intensity, and quantifying the cooling benefits of tree shade through an outdoor urban physical scale model with field measurement. The proposed method for carrying out the analysis in a 3D environment is an important first step in relating local level decision making to positive regional and global change.

\section{Acknowledgements}

This material is based upon work supported by the National Science Foundation under Grant SES-0951366, Decision Center for a Desert City II: Urban Climate Adaptation. Any opinions, findings, and conclusions or recommendations expressed in this material are those of the authors and do not necessarily reflect the views of the National Science Foundation. Qunshan Zhao is partly supported by the National Natural Science Foundation of China (No. 51378399 and 41331175). The authors would like to thank DeltaCodes who provided an education discount for the Shadow Analysis Sketchup plugin and the anonymous reviewers for their valuable comments and suggestions to improve the manuscript.

\section{References}

[1] H.H. Kim, Urban heat island, Int. J. Remote Sens. 13 (1992) 2319-2336. doi: $10.1080 / 01431169208904271$. 
1 [2] L.M. Gartland, Heat Islands: Understanding and Mitigating Heat in Urban Areas, Routledge, 2012.

[3] M. Santamouris, On the energy impact of urban heat island and global warming on buildings, Energy Build. 82 (2014) 100-113.

[4] K.L. Bassil, D.C. Cole, Effectiveness of Public Health Interventions in Reducing Morbidity and Mortality during Heat Episodes: a Structured Review, Int. J. Environ. Res. Public. Health. 7 (2010) 991-1001. doi:10.3390/ijerph7030991.

[5] P. Bi, S. Williams, M. Loughnan, G. Lloyd, A. Hansen, T. Kjellstrom, K. Dear, A. Saniotis, The Effects of Extreme Heat on Human Mortality and Morbidity in Australia: Implications for Public Health, Asia. Pac. J. Public Health. (2011) 1010539510391644. doi: $10.1177 / 1010539510391644$.

[6] M.A. McGeehin, M. Mirabelli, The potential impacts of climate variability and change on temperature-related morbidity and mortality in the United States., Environ. Health Perspect. 109 (2001) 185-189.

[7] C.J. Tomlinson, L. Chapman, J.E. Thornes, C.J. Baker, Including the urban heat island in spatial heat health risk assessment strategies: a case study for Birmingham, UK, Int. J. Health Geogr. 10 (2011) 42. doi:10.1186/1476-072X-10-42.

[8] H. Akbari, M. Pomerantz, H. Taha, Cool surfaces and shade trees to reduce energy use and improve air quality in urban areas, Sol. Energy. 70 (2001) 295-310.

[9] C.-R. Chang, M.-H. Li, S.-D. Chang, A preliminary study on the local cool-island intensity of Taipei city parks, Landsc. Urban Plan. 80 (2007) 386-395. doi:10.1016/j.landurbplan.2006.09.005.

[10] Z.-H. Wang, X. Zhao, J. Yang, J. Song, Cooling and energy saving potentials of shade trees and urban lawns in a desert city, Appl. Energy. 161 (2016) 437-444. doi:10.1016/j.apenergy.2015.10.047.

[11] A. Middel, N. Chhetri, R. Quay, Urban forestry and cool roofs: Assessment of heat mitigation strategies in Phoenix residential neighborhoods, Urban For. Urban Green. 14 (2015) 178-186. doi:10.1016/j.ufug.2014.09.010.

[12] J. Gui, P. Phelan, K.E. Kaloush, J.S. Golden, Impact of Pavement Thermophysical Properties on Surface Temperatures, J. Mater. Civ. Eng. 19 (2007) 683-690. doi:10.1061/(ASCE)0899-1561(2007)19:8(683).

[13] J.S. Golden, J. Carlson, K.E. Kaloush, P. Phelan, A comparative study of the thermal and radiative impacts of photovoltaic canopies on pavement surface temperatures, Sol. Energy. 81 (2007) 872-883. doi:10.1016/j.solener.2006.11.007.

[14] Q. Zhao, S.W. Myint, E.A. Wentz, C. Fan, Rooftop Surface Temperature Analysis in an Urban Residential Environment, Remote Sens. 7 (2015) 12135-12159. doi:10.3390/rs70912135.

[15] Z. Tan, K.K.-L. Lau, E. Ng, Urban tree design approaches for mitigating daytime urban heat island effects in a high-density urban environment, Energy Build. (2015). doi:10.1016/j.enbuild.2015.06.031.

[16] H. Akbari, Shade trees reduce building energy use and $\mathrm{CO} 2$ emissions from power plants, Environ. Pollut. 116 (2002) S119-S126.

[17] R. Pandit, D.N. Laband, Energy savings from tree shade, Ecol. Econ. 69 (2010) 1324-1329. doi:10.1016/j.ecolecon.2010.01.009. 
[18] A.V. Parisi, M.G. Kimlin, J.C.F. Wong, M. Wilson, Diffuse component of solar ultraviolet radiation in tree shade, J. Photochem. Photobiol. B. 54 (2000) 116-120. doi:10.1016/S1011-1344(00)00003-8.

[19] E.A. Wentz, S. Rode, X. Li, E.M. Tellman, B.L. Turner, Impact of Homeowner Association (HOA) landscaping guidelines on residential water use, Water Resour. Res. (2016) n/a-n/a. doi:10.1002/2015WR018238.

[20] M. Fogl, V. Moudrý, Influence of vegetation canopies on solar potential in urban environments, Appl. Geogr. 66 (2016) 73-80. doi:10.1016/j.apgeog.2015.11.011.

[21] R. Levinson, H. Akbari, M. Pomerantz, S. Gupta, Solar access of residential rooftops in four California cities, Sol. Energy. 83 (2009) 2120-2135. doi:10.1016/j.solener.2009.07.016.

[22] Z. Li, Z. Zhang, K. Davey, Estimating geographical pv potential using lidar data for buildings in downtown san francisco, Trans. GIS. 19 (2015) 930-963.

[23] T.R. Tooke, N.C. Coops, J.A. Voogt, M.J. Meitner, Tree structure influences on rooftop-received solar radiation, Landsc. Urban Plan. $102 \quad$ (2011) 73-81. doi:10.1016/j.landurbplan.2011.03.011.

[24] J.R. Simpson, E.G. McPherson, Potential of tree shade for reducing residential energy use in California, J. Arboric. 22 (1996) 10-18.

[25] G. McPherson, J.R. Simpson, P.J. Peper, S.E. Maco, Q. Xiao, E. Mulrean, Desert southwest community tree guide: benefits, costs and strategic planting, (2004). http://www.treesearch.fs.fed.us/pubs/47703 (accessed April 10, 2016).

[26] W.H. Hwang, P.E. Wiseman, V.A. Thomas, Tree Planting Configuration Influences Shade on Residential Structures in Four US Cities., Arboric. Urban For. 41 (2015). http://urbanforestry.frec.vt.edu/documents/articles/Hwang_AUF_2015.pdf (accessed April 10, 2016).

[27] M. Sawka, A.A. Millward, J. Mckay, M. Sarkovich, Growing summer energy conservation through residential tree planting, Landsc. Urban Plan. 113 (2013) 1-9. doi:10.1016/j.landurbplan.2013.01.006.

[28] F. Calcerano, L. Martinelli, Numerical optimisation through dynamic simulation of the position of trees around a stand-alone building to reduce cooling energy consumption, Energy Build. 112 (2016) 234-243. doi:10.1016/j.enbuild.2015.12.023.

[29] R. Berry, S.J. Livesley, L. Aye, Tree canopy shade impacts on solar irradiance received by building walls and their surface temperature, Build. Environ. 69 (2013) 91-100. doi:10.1016/j.buildenv.2013.07.009.

[30] V.M. Gomez-Munoz, M.A. Porta-Gándara, J.L. Fernández, Effect of tree shades in urban planning in hot-arid climatic regions, Landsc. Urban Plan. 94 (2010) 149-157. doi:10.1016/j.landurbplan.2009.09.002.

[31] G. Lee, 3D coverage location modeling of Wi-Fi access point placement in indoor environment, Comput. Environ. Urban Syst. (2015). doi:10.1016/j.compenvurbsys.2015.05.002.

[32] Y.J. Huang, H. Akbari, H. Taha, A.H. Rosenfeld, The potential of vegetation in reducing summer cooling loads in residential buildings, J. Clim. Appl. Meteorol. 26 (1987) 1103-1116.

[33] H. Akbari, H. Taha, The impact of trees and white surfaces on residential heating and cooling energy use in four Canadian cities, Energy. 17 (1992) 141-149. 
[34] H. Safarzadeh, M.N. Bahadori, Passive cooling effects of courtyards, Build. Environ. 40 (2005) 89-104. doi:10.1016/j.buildenv.2004.04.014.

[35] J. Ordóñez, E. Jadraque, J. Alegre, G. Martínez, Analysis of the photovoltaic solar energy capacity of residential rooftops in Andalusia (Spain), Renew. Sustain. Energy Rev. 14 (2010) 2122-2130. doi:10.1016/j.rser.2010.01.001.

[36] H. Huang, C.-C. Ni, X. Ban, J. Gao, A. Schneider, S. Lin, Connected Wireless Camera Network Deployment with Visibility Coverage, in: 2014: pp. 1204-1212.

[37] K.A. Amriki, P.K. Atrey, Bus surveillance: how many and where cameras should be placed, Multimed. Tools Appl. 71 (2014) 1051-1085. doi:10.1007/s11042-012-1247-1.

[38] C. Toregas, R. Swain, C. ReVelle, L. Bergman, The location of emergency service facilities, Oper. Res. 19 (1971) 1363-1373.

[39] R. Church, C. ReVelle, The maximal covering location problem, Pap. Reg. Sci. 32 (1974) 101-118.

[40] F. Letourneux, Y. Corre, E. Suteau, Y. Lostanlen, 3D coverage analysis of LTE urban heterogeneous networks with dense femtocell deployments, EURASIP J. Wirel. Commun. Netw. 2012 (2012) 1-14.

[41] T. Podobnikar, A. Vrečko, Digital Elevation Model from the Best Results of Different Filtering of a LiDAR Point Cloud, Trans. GIS. 16 (2012) 603-617. doi:10.1111/j.1467-9671.2012.01335.x.

[42] M.F. Goodchild, J. Lee, Coverage problems and visibility regions on topographic surfaces, Ann. Oper. Res. (1989) 175-186.

[43] Y.-H. Kim, S. Rana, S. Wise, Exploring multiple viewshed analysis using terrain features and optimisation techniques, Comput. Geosci. 30 (2004) 1019-1032. doi:10.1016/j.cageo.2004.07.008.

[44] A.T. Murray, K. Kim, J.W. Davis, R. Machiraju, R. Parent, Coverage optimization to support security monitoring, Comput. Environ. Urban Syst. 31 (2007) 133-147. doi:10.1016/j.compenvurbsys.2006.06.002.

[45] S. Bao, N. Xiao, Z. Lai, H. Zhang, C. Kim, Optimizing watchtower locations for forest fire monitoring using location models, Fire Saf. J. 71 (2015) 100-109. doi:10.1016/j.firesaf.2014.11.016.

[46] T.H.D. Dao, Y. Zhou, J.-C. Thill, E. Delmelle, Spatio-temporal location modeling in a 3D indoor environment: the case of AEDs as emergency medical devices, Int. J. Geogr. Inf. Sci. 26 (2012) 469-494. doi:10.1080/13658816.2011.597753.

[47] Q. Zhao, E.A. Wentz, A.T. Murray, Shade Optimization in a Desert Environment, in: Ext. Abstr. Proc. GIScience 2014, 2014: pp. 118-121. https://www.researchgate.net/profile/Qunshan_Zhao/publication/271215424_Shade_Optimi zation_in_a_Desert_Environment/links/54c2c98c0cf256ed5a8f950c.pdf (accessed April 22, 2016).

[48] US Census Bureau., 2010 Demographic Profile Data, (n.d.). https://factfinder.census.gov/faces/tableservices/jsf/pages/productview.xhtml?src=CF (accessed September 15, 2016).

[49] Urban Tree Scientist - Central Arizona-Phoenix Long-Term Ecological Research, Cent. Ariz. Long-Term Ecol. https://sustainability.asu.edu/caplter/collaborations/shadetree/ (accessed June 10, 2016).

[50] Eligible desert-adaptive shade trees, Srpnet. (n.d.). http://www.savewithsrp.com/RD/shadetreetypes.aspx (accessed June 9, 2016). 
1 [51] J.A. Duffie, Solar engineering of thermal processes / John A. Duffie, William A. Beckman, 4th ed, John Wiley, Hoboken, 2013.

[52] R.L. Church, A.T. Murray, Business site selection, location analysis, and GIS, Wiley, Hoboken, N.J, 2009.

[53] City of Tempe, AZ: Zoning and Development Code - Part 4: Development Standards, 2011. http://www.tempe.gov/home/showdocument?id=1914 (accessed June 9, 2016).

[54] City of Tempe, AZ: Zoning and Development Code - Appendix, 2011. http://www.tempe.gov/home/showdocument?id=1910 (accessed June 9, 2016).

[55] J.A. Wagar, Using vegetation to control sunlight and shade on windows, Landsc. J. 3 (1984) 24-35.

[56] G.M. Heisler, Energy savings with trees, (1986). http://www.treesearch.fs.fed.us/pubs/34773 (accessed December 15, 2016).

[57] E. Shaviv, A. Yezioro, Analyzing mutual shading among buildings, Sol. Energy. 59 (1997) 83-88.

[58] M. Pidwirny, Earth-Sun Relationships and Insolation, Fundam. Phys. Geogr. 2 (2006).

[59] D. Armson, M.A. Rahman, A.R. Ennos, A comparison of the shading effectiveness of five different street tree species in Manchester, UK, Arboric. Urban For. 39 (2013) 157-164.

[60] M.A. Rahman, D. Armson, A.R. Ennos, A comparison of the growth and cooling effectiveness of five commonly planted urban tree species, Urban Ecosyst. 18 (2015) 371-389. doi:10.1007/s11252-014-0407-7. 